
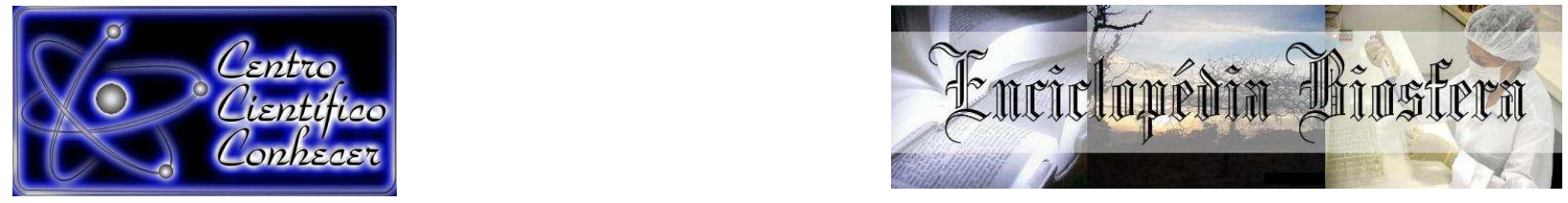

\title{
ASPECTOS HISTOLÓGICOS DE VÍSCERAS DE PIRAPITINGA (Piaractus brachypomus)
}

Gabriella Canedo Costa ${ }^{1}$, Luana de Sousa Ribeiro ${ }^{1}$, Idayana Zarpellon, Fernanda, Gomes de Paula ${ }^{2}$, Ana Paula Iglesias Santin ${ }^{3}$

1 Discente de Medicina Veterinária, EVZ/UFG, Goiânia, Goiás, Brasil

2 Professora Adjunta, Depto Med. Vet., EVZ/UFG.

3 Professora Adjunta Depto de Zootecnia, EVZ/UFG (apisantin@gmail.com)

Recebido em: 02/10/2017 - Aprovado em: 21/11/2017 - Publicado em: 05/12/2017 DOI: 10.18677/EnciBio_2017B6

\section{RESUMO}

O Brasil apresenta condições favoráveis e uma enorme biodiversidade para a ampliação da atividade pesqueira. O pirapitinga ocupa terceiro lugar entre as espécies cultivadas no país. Este trabalho tem como objetivo descrever as características microscópicas normais de vísceras da espécie Piaractus brachypomus, o pirapitinga. Foram usados vinte animais provenientes dos criatórios do Departamento de Zootecnia da Escola de Veterinária e Zootecnia da Universidade Federal de Goiás (EVZ/UFG). A descrição microscópica possibilitou maior conhecimento sobre diferentes órgãos como, coração, brânquias, diferentes porções do intestino, baço, hepatopâncreas e rins, como também permitiu a observação de diferenças entre as espécies, viabilizando futuros experimentos envolvendo as patologias ou práticas de manejo inadequadas que prejudiquem a criação do pirapitinga.

PALAVRAS-CHAVE: Baço, Intestino, Microscopia, Peixe.

\section{HISTOLOGIC ASPECTS OF PIRAPITINGA (Piaractus brachypomus) VISCERAS}

\begin{abstract}
Brazil have advantageous conditions and high biodiversity for improvement of fishing activity. Piaractus brachypomus is the third most produced species in the country. The purpose of this study is to describe microscopic features of normal viscera. It was used twenty specimens from Fish farming of the Escola de Veterinária e Zootecnia of the Universidade Federal de Goiás (EVZ/UFG). The histological description made it possible to increase knowledge about different organs such as heart, gills, and different portions of the intestine, spleen, kidneys and liver. Some differences were observed in relation to other fish species, providing further studies on pathological conditions or inadequate management practices that can harm Pirapitinga production.
\end{abstract}

KEYWORDS: Spleen, Intestine, Microscopy, Fish

\section{INTRODUÇÃO}

A atividade da pesca possui grande importância mundial. O Brasil por apresentar condições favoráveis, enorme biodiversidade, $12 \%$ da água doce do mundo e uma costa marítima de $8500 \mathrm{~km}$, tem excelentes condições à atividade 
pesqueira. Sua piscicultura vem se desenvolvendo nos últimos anos, e juntamente com essa intensificação, os criatórios passaram a apresentar elevada densidade populacional, no entanto há grande despreparo no manejo destas criações, fator que favorece o surgimento de diversas doenças (SIDÔNIO et al., 2012; PEREIRA et al., 2013; SANTOS et al., 2013; SILVA, 2017).

Segundo Cavichiolo (2009), as situações de estresse nos criatórios são bastante comuns, o que resulta na redução do desempenho e no aparecimento de doenças. Neste sentido, as lesões macroscópicas podem demorar a se apresentar, porém com um estudo microscópico pode-se chegar ao diagnóstico mais precocemente.

Estudos ambientais também podem ser realizados pela avalição histológica de órgãos de peixes. Para verificar a qualidade do meio ambiente, alguns pesquisadores analisaram microscopicamente as brânquias (PEREIRA et al., 2014), enquanto outro trabalho verificou a presença de alterações histopatológicas no fígado de Poecilia vivipara (PAULO et al., 2012). Portanto, é fundamental o conhecimento da histologia de cada espécie, na região onde é criada, possibilitando, posteriormente, a observação de alterações que ocorram nas diferentes enfermidades, sendo estas decorrentes de fatores ambientais ou de manejos inadequados.

Entre as espécies em destaque, na região Centro-Oeste, encontra-se a Pirapitinga (Piaractus brachypomus), teleósteo de água doce, da família Characidae, nativo da Amazônia e com grande importância para piscicultura brasileira. É uma espécie rústica, de crescimento rápido, além de atingir excelente valor de mercado, despertando interesse nacional (RIBEIRO, et al. 2016a).

Diante do exposto a compreensão histológica dos órgãos de peixes vem como outra ferramenta de auxílio que permitirá a comparação com órgãos afetados por enfermidades e dessa forma propiciará um maior controle das doenças nos criatórios. Portanto, objetivo deste trabalho foi o de descrever as características microscópicas normais de vísceras da espécie Piaractus brachypomus.

\section{MATERIAL E MÉTODOS}

A experimentação foi conduzida nos criatórios do Departamento de Zootecnia e no Setor de Patologia Animal (SPA) da EVZ/UFG. Sendo avaliados órgãos viscerais de pirapitinga (Piaractus brachypomus). Para tanto foram utilizados 20 animais, pesando aproximadamente $0,350 \mathrm{Kg}$. O estudo foi desenvolvido entre 0 mês de agosto do ano 2013, estendendo-se até o mês de junho do ano de 2014. Estes peixes seriam destinados à comercialização e alimentação humana.

Para evitar-se a autólise dos órgãos, a retirada destes foi feita no criatório e logo em seguida coração, brânquias, baço, hepatopâncreas, rins e intestino foram adequadamente coletados e distribuídos em potes, com identificação, contendo formol tamponado a $10 \%$.

As amostras ficaram $48 \mathrm{~h}$ na solução fixadora visando a preservação adequada do material biológico. Em seguida, foi desidratado e sofreu parafinização. Posteriormente foram realizados cortes de $3 \mu \mathrm{m}$, estendidos em lâminas de vidro e com hematoxilina e eosina foram corados, seguindo a metodologia padrão utilizada no SPA/ EVZ/UFG. A leitura histológica das amostras foi feita com microscopia óptica.

O projeto, cadastrado no SAP da UFG sob o número 39543 não foi encaminhado ao Comitê de Ética da UFG, por utilizar para este estudo animais previamente abatidos para fins comerciais, destinados a consumo humano. Desta 
entendeu-se ser dispensável a avaliação deste Comitê, de acordo com o seu regimento, baseado na Lei ํo 11.794/2008 de 8 de outubro de 2008 e o Decreto no 6.899/2009 de 15 de julho de 2009.

\section{RESULTADOS E DISCUSSÃO}

As brânquias, do Piaractus brachypomus, encontram-se localizadas na cavidade orofaríngea. Nestas foram observadas lamelas denominadas primárias, já as lamelas secundárias apresentavam-se localizadas acima e abaixo do eixo longitudinal, das lamelas primárias (Figura 1). Os tipos celulares que constituíam o filamento da região basal até a superfície do epitélio eram as células cloreto e células epiteliais pavimentosas. As lamelas eram compartimentalizadas internamente pelas células pilares. Os arcos branquiais possuíam um suporte de cartilagem hialina. Descrição semelhante foi realizada por outros pesquisadores, os quais ainda citaram a observação de células mucosas (MORRISON, 2007; GENTEN et al., 2009; ALMEIDA et al., 2015).

O coração estava situado atrás dos arcos branquiais. Verificou-se histologicamente o lúmen atrial apresentava-se pequeno e que era mais delgado do que ventricular. Este último era caracterizado por um miocárdio esponjoso e músculo compacto e, as fibras musculares do miocárdio formavam feixes, os quais encontravam-se distribuídos em orientações variadas (Figura 2), como observado por Almeida et al. (2015). Em epicárdio, a camada mais externa era caracterizada por células pavimentosas simples e conjuntivo do tipo frouxo. $O$ bulbo arterioso constituído de conjuntivo do tipo elástico e de fibras da musculatura lisa situadas em sentidos diversos, também foi verificado por Genten et al. (2009). O mesmo era envolvido por tecido conjuntivo frouxo e tecido epitelial simples pavimentoso, formando a serosa do órgão (Figura 3).

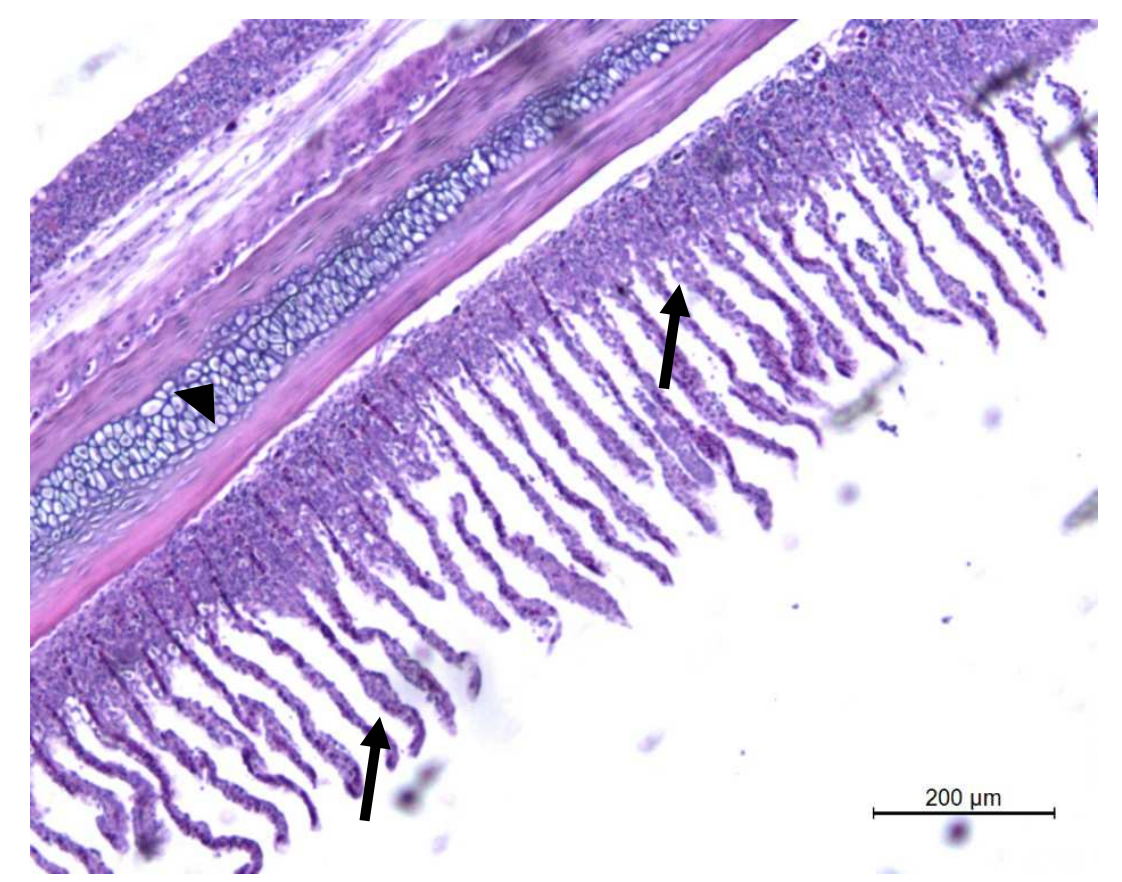

FIGURA 1: Fotomicroscopia de brânquia de Pirapitinga, destacando-se lamela primária com suporte de cartilagem hialina (ponta de seta) e lamelas secundárias (seta). H\&E, aumento de 50x. 


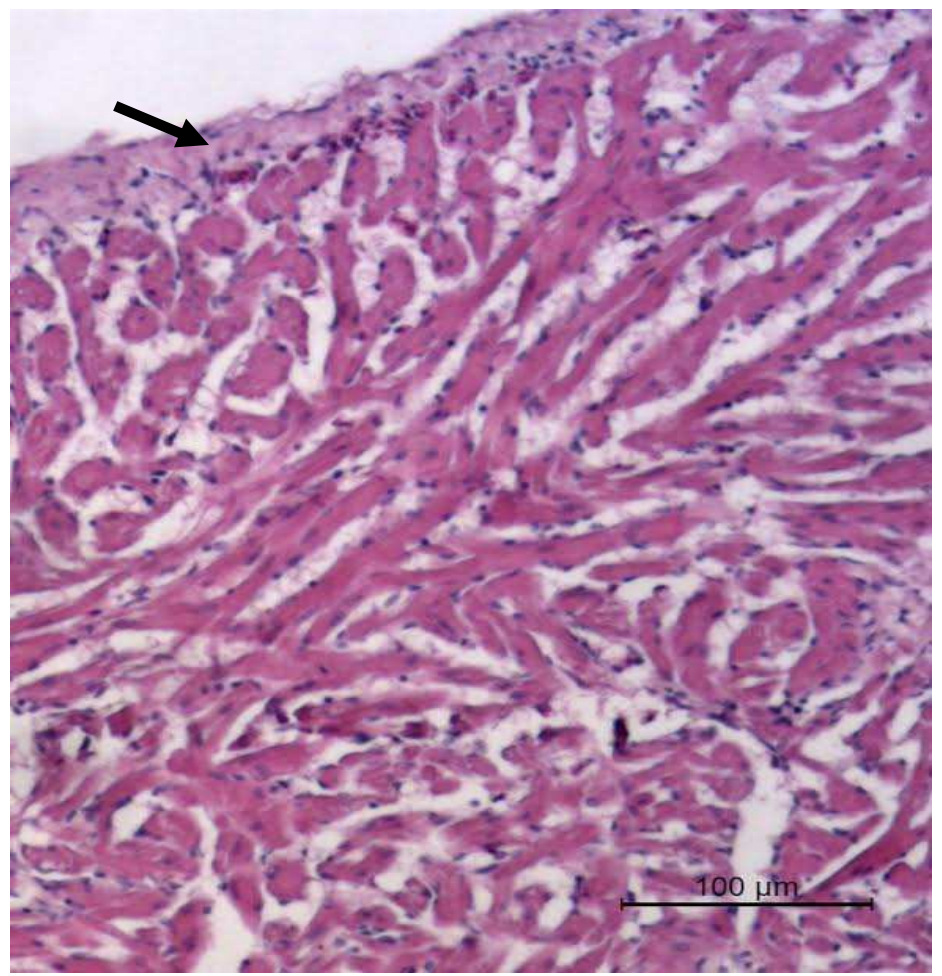

FIGURA 2: Fotomicroscopia de coração de Pirapitinga.

Fibras musculares do miocárdio apresentando orientações variadas. Sendo este envolvido pelo epicárdio (seta). H\&E, aumento de 100x.

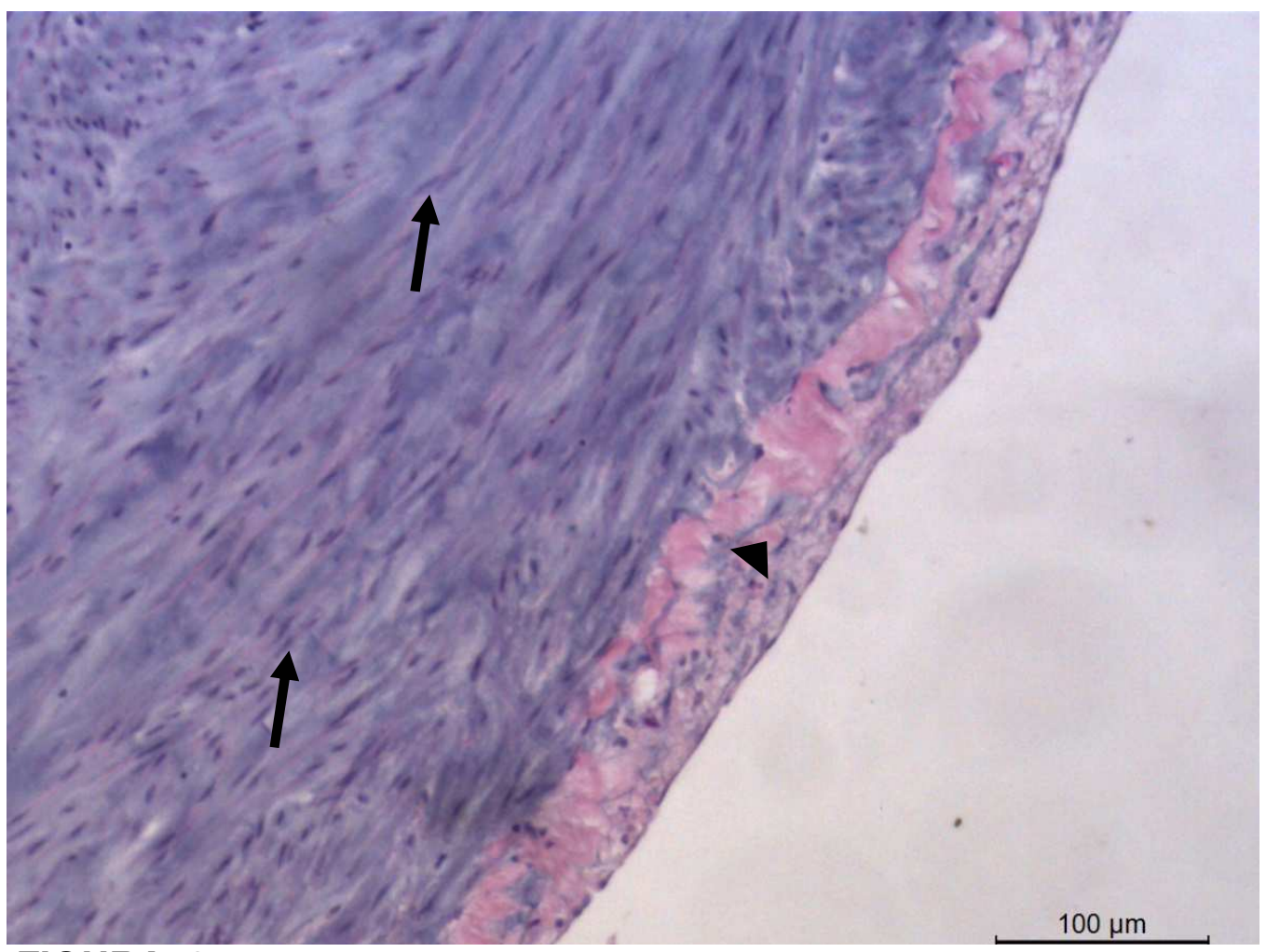

FIGURA 3: Fotomicroscopiade bulbo arterioso de Pirapitinga. Disposição tecidual em diferentes sentidos, verificando-se fibras da musculatura lisa (seta) e serosa localizada mais externamente (ponta de seta), H\&E. aumento de 100x. 
A localização anatômica do hepatopâncreas, na cavidade celomática, é ventral à bexiga natatória e craniodorsal ao estômago. Na avaliação histológica não se constatou padrão trabecular hepático e veia hepática terminal como verificado em mamíferos. Porém, notou-se o desenvolvimento de cordões anastomosados, sinusóides e células de Kupffer. Os hepatócitos apresentavam coloração citoplasmática acidófila, formato poliédrico e grande quantidade de glicogênio formando vacúolos intracitoplasmáticos. O núcleo dos hepatócitos ocupava 10 a $20 \%$ da célula, localização central, com formato arredondado, de tonalidade basófila e nucléolo proeminente. Foram observados vários hepatócitos binucleados (Figura 4). Características similares foram mencionadas por Morrison (2007); Cavichiolo (2009) e Oliveira et al. (2013), e do mesmo modo verificaram uma redução na tendência à formação de tríades portais e também de lóbulos.

O ducto biliar encontrava-se no parênquima hepática e era constituído por um epitélio simples cilíndrico de citoplasma acidófilo e núcleo de coloração basofílica localizado na região basal das células. O mesmo era envolvido por conjuntivo do tipo frouxo mesclado com tecido muscular e na maioria das vezes encontrava-se acompanhado por uma arteríola (Figura 4). Envolvendo o hepatopâncreas tem-se uma cápsula constituída por diminuto estroma associado a tecido epitelial simples pavimentoso. Constituição semelhante foi notada em outros estudos, mas não relataram arteríola central adjacente ao ducto (GENTEN et al., 2009).

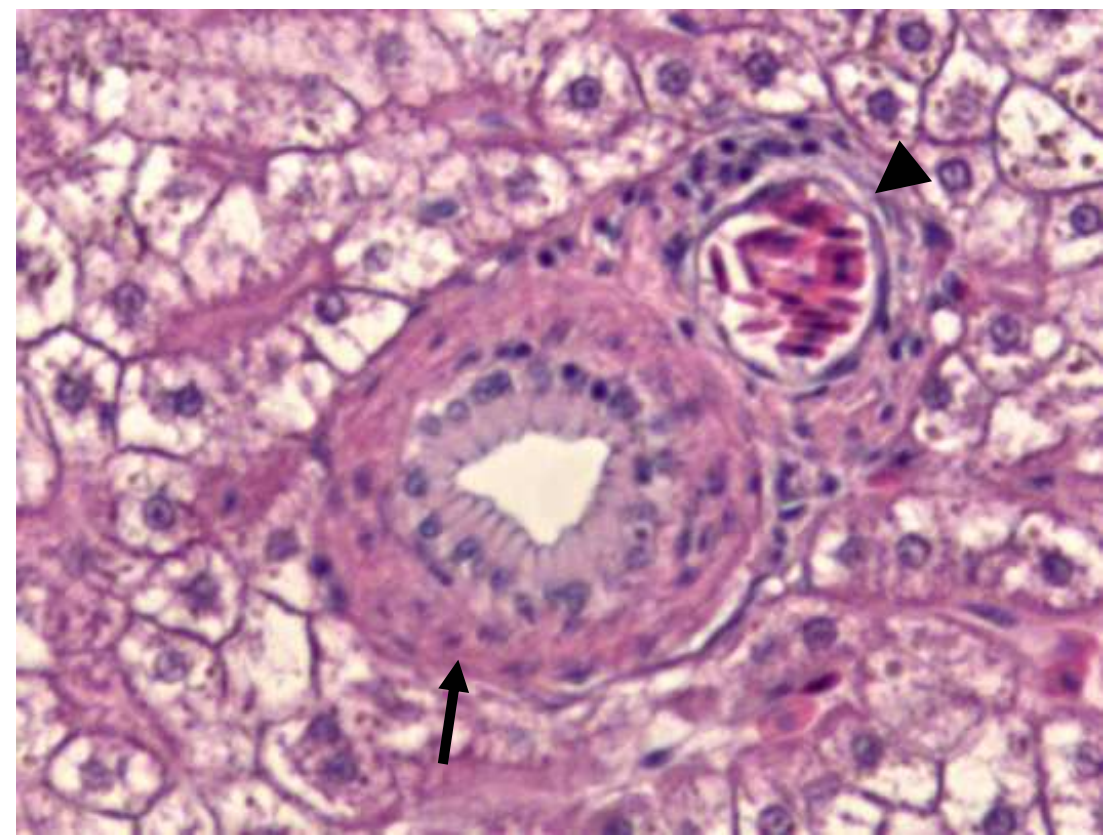

FIGURA 4: Fotomicroscopia de hepatopâncreas de Pirapitinga. Observar o glicogênio formando vacúolos no citoplasma de hepatócitos e ducto biliar envolvido por estroma (seta), associado à arteríola (ponta de seta). H\&E, aumento de 200x.

No pâncreas associado ao fígado (Figura 5), notou-se células acinares de formato poliédrico com coloração citoplasmática discretamente basofílica, sendo o mesmo pouco aparente devido ao elevado número de grânulos de zimogênio acidófilos. O núcleo tinha tonalidade basofílica, com nucléolo aparente. Descrição equivalente foi verificada por Costa et al. (2012). Por sua vez Oliveira et al. (2013), os quais trabalharam com a espécie Astronotus ocellatus, observaram revestimento hepático constituído por tecido epitelial cilíndrico, aspecto que não descrito na 
literatura consultada, não sendo igualmente observada na histologia dos mamíferos.

O baço apresentava-se justaposto ao fígado na cavidade celomática e era constituído internamente por células do sistema retículo endotelial, formando polpa vermelha e branca difusas, diferente do observado em mamíferos, não havia zona marginal limitando polpa vermelha e branca (Figura 6). Além disso, a quantidade de estroma no interior do parênquima era escassa, Morrison (2007) e Maciel et al. (2012) fizeram relato semelhante. Genten et al. (2009) mencionaram células elipsóides, não sendo estas observadas neste experimento. Ledic-eto et al. (2014) também observaram camada serosa e melanomacrófagos e acrescentaram a observação de eosinófilos dispersos, fato que não foi notado neste estudo.

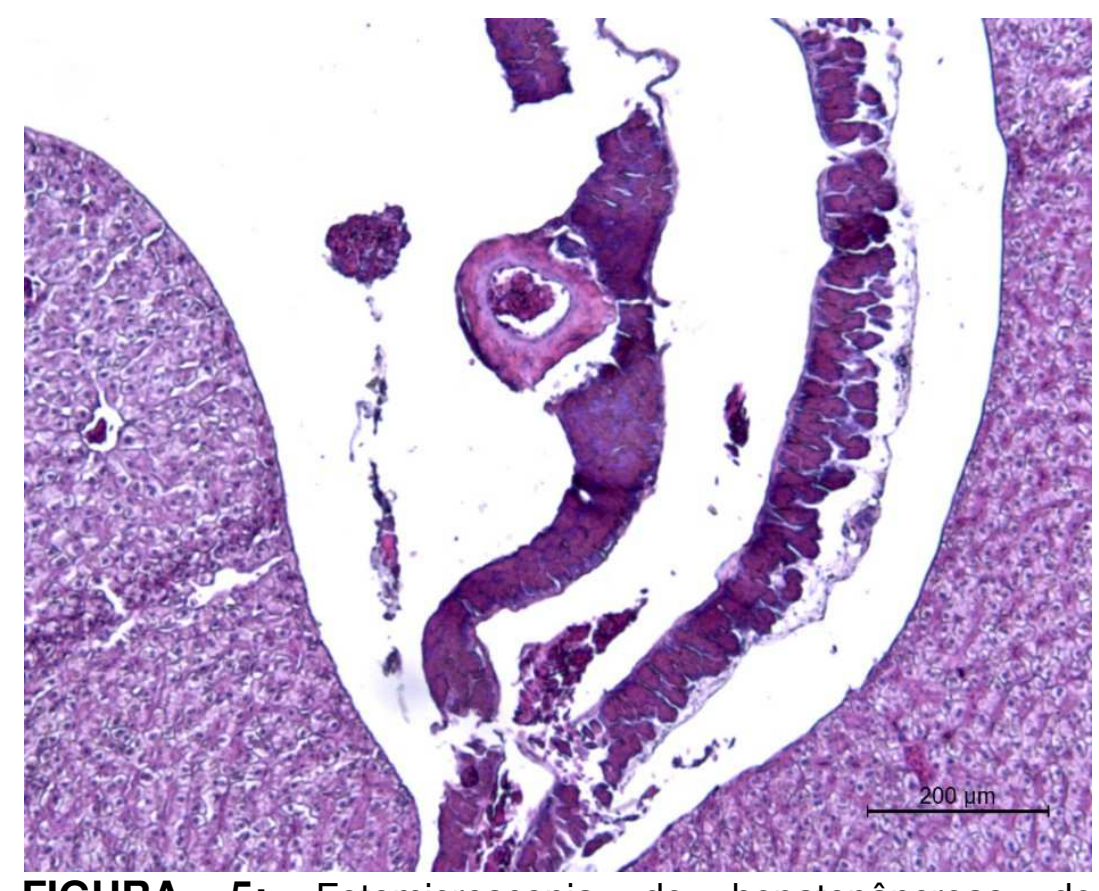

FIGURA 5: Fotomicroscopia de hepatopâncreas de Pirapitinga, evidenciando o pâncreas (seta). H\&E, aumento de 50x.

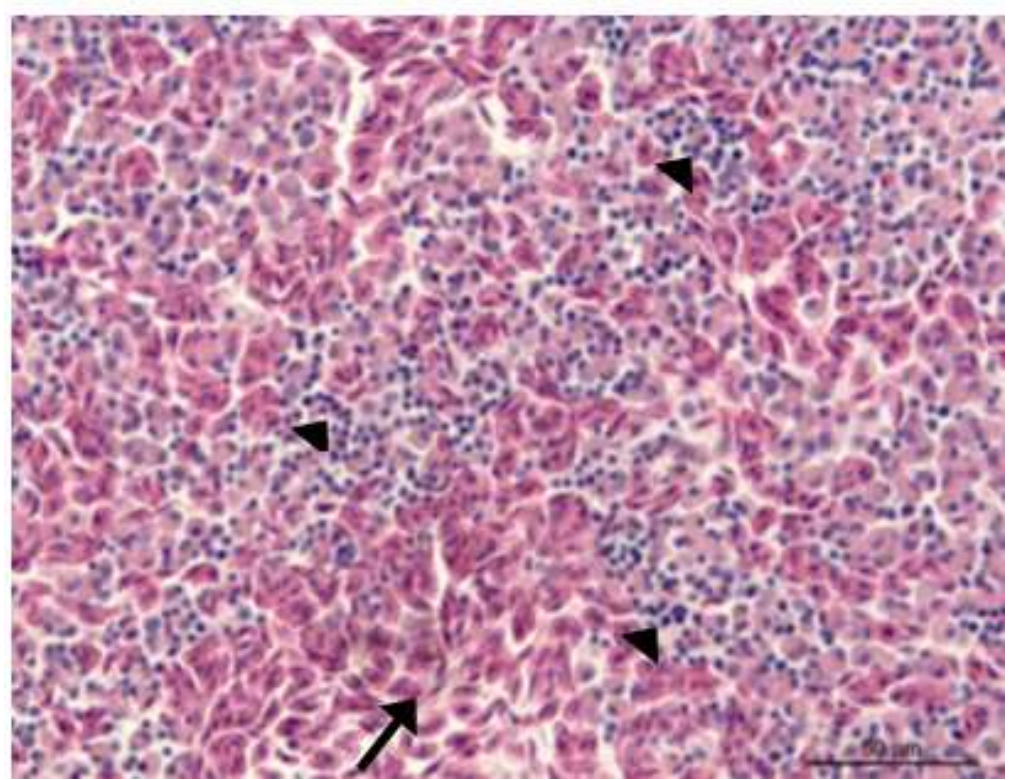

FIGURA 6: Fotomicroscopia de baço de Pirapitinga, evidenciando polpa vermelha (seta) e polpa branca de distribuição difusa (ponta de seta). H\&E, aumento de 100x. 
O rim localizava-se na cavidade celomática retroperitonealmente na região dorsal, dorsalmente à bexiga natatória e ventralmente à coluna vertebral. No parênquima renal os néfrons eram compostos por corpúsculo renal, glomérulo, espaço de Bowmann e cápsula de Bowmann. Seu estroma era composto por células hematopoiéticas e foi observado melanomacrófagos dispersos no mesmo (Figura 7). Constituição renal semelhante também foi descrita por Morrison (2007).

Os túbulos contorcidos proximais eram formados por um epitélio simples cúbico, com microvilosidades, citoplasma eosinofílico, núcleo arredondado e basofílico, ocupando $50 \%$ do volume celular. Os túbulos contorcidos distais também eram constituídos por um epitélio simples cúbico, citoplasma acidófilo, porém um pouco mais claro comparado ao túbulo contorcido proximal, e núcleo arredondado. Já os ductos coletores renais eram compostos por epitélio simples cilíndrico, citoplasma acidófilo, núcleo basofílico, arredondado e em localização basal (Figura 7). Envolvendo os ductos havia tecido estromal e musculatura lisa. As descrições dos túbulos contorcidos e dos ductos coletores estão em conformidade com os relatos de Ribeiro et al. (2016b).

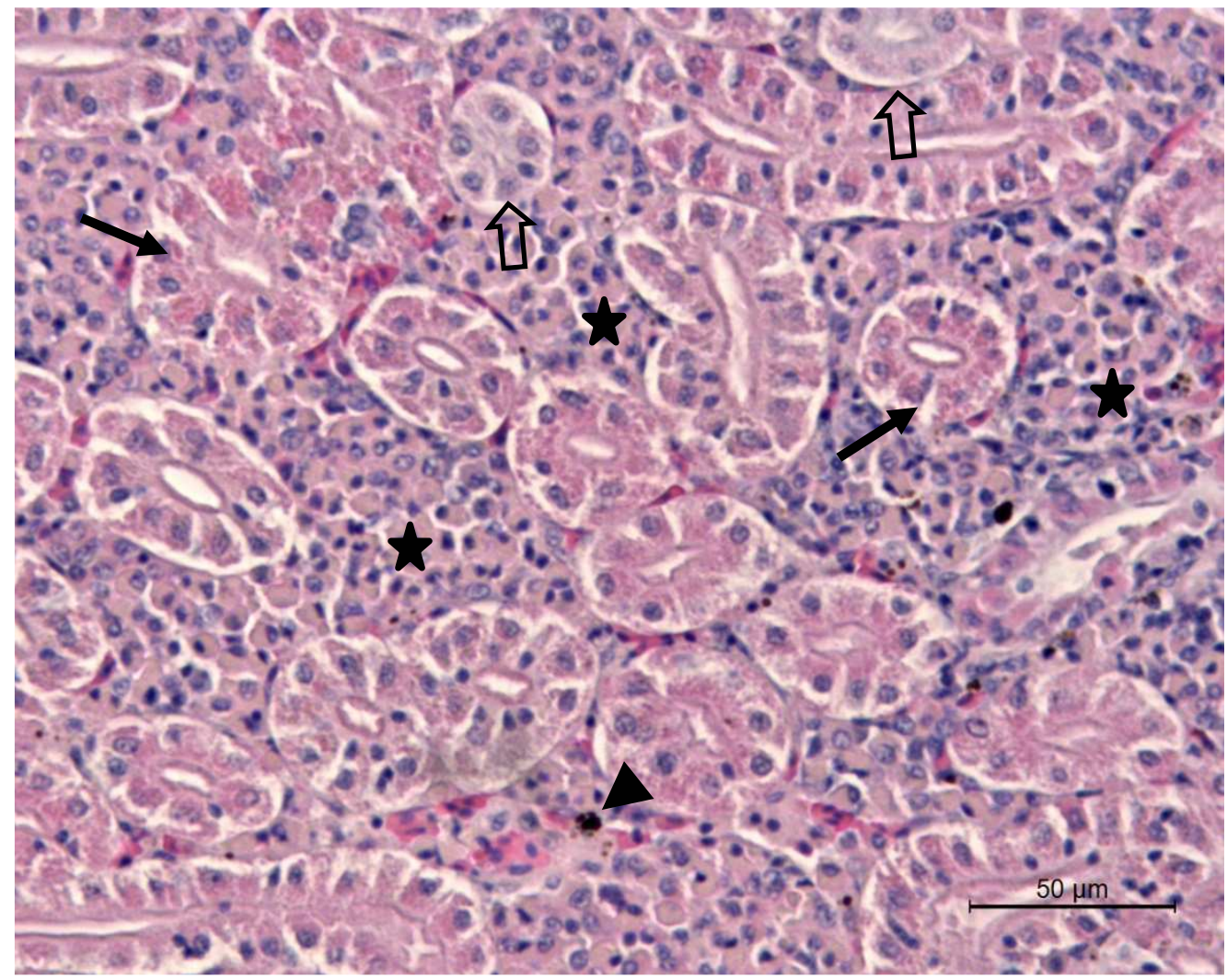

FIGURA 7: Fotomicroscopiade rim de Pirapitinga. Estroma com células hematopoiéticas (estrela) e melanomacrófagos (ponta de seta). Túbulos contorcidos proximais (setas) com citoplasma fortemente eosinofílico, microvilosidades e túbulos contorcidos distais levemente eosinofílicos (seta vazada). $\mathrm{H} \& \mathrm{E}$, aumento de 200x.

O intestino foi dividido em três segmentos, intestino anterior, médio e posterior, o pâncreas encontrava-se associado a todos os segmentos. No terço anterior da cavidade peritoneal estava localizado o intestino anterior, no terço médio estava o intestino médio e no terço posterior o intestino posterior que se estendia até 
ânus e se abria anteriormente à nadadeira anal. Esta mesma divisão foi utilizada por Maciel et al. (2012), porém Cavichiolo (2009), ainda acrescentou a porção cefálica antecedendo a porção anterior.

O intestino anterior era constituído por um epitélio simples cilíndrico com células epiteliais de coloração acidófila, com células caliciformes. O núcleo era oval e predominantemente centralizado, ocupando $25 \%$ do volume da mesma. Lâmina própria formada por conjuntivo do tipo frouxo. Na mucosa a camada muscular era constituída por musculatura lisa, invadindo as longas vilosidades. A submucosa era delgada, constituída por tecido conjuntivo frouxo. Camada muscular formada por circular interna e transversal externa, um pouco mais delgada que a anterior, ambas eram formadas por fibras musculares lisas (Figura 8).

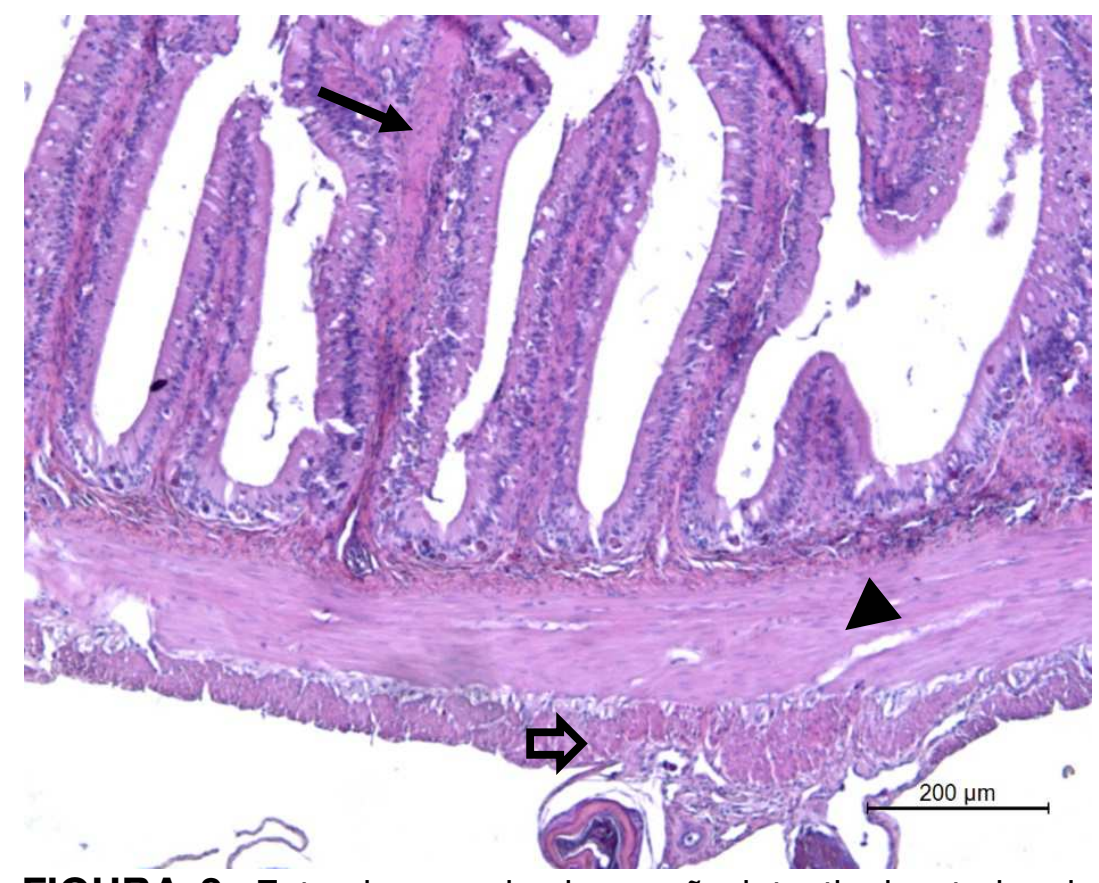

FIGURA 8: Fotomicroscopia da porção intestinal anterior de Pirapitinga, com vilosidades longas e tecido muscular liso no seu interior (setas), são revestidas por epitélio simples cilíndrico e núcleo com morfologia alongada, localizado na região basal. Possui uma camada muscular circular interna (ponta de seta cheia) e uma camada muscular transversal externa (seta vazada). $\mathrm{H} \& \mathrm{E}$, aumento de 50x.

Os intestinos médio e posterior eram semelhantes, com algumas particularidades entre si. Possuíam um epitélio simples cilíndrico alto, com citoplasma acidófilo, vesículas intracitoplasmáticas, núcleo com morfologia alongada e basofílico, na região basal da célula, observou-se células caliciformes. A lâmina própria formada por conjuntivo do tipo frouxo. Musculatura lisa estava presente na mucosa dos órgãos, invadindo as vilosidades e presente somente no intestino médio. As vilosidades, quando comparadas com as da porção anterior do intestino, eram mais curtas. A submucosa era caracterizada por tecido conjuntivo frouxo. A camada muscular era formada por uma camada circular interna e uma transversal externamente, como no intestino anterior.

Chatchavalvanich et al. (2006) também descreveram de forma similar o ENCICLOPÉDIA BIOSFERA, Centro Científico Conhecer - Goiânia, v.14 n.26; p.71 2017 
epitélio intestinal e ainda observou o epitélio cilíndrico estratificado na porção posterior do órgão e Maciel et al. (2012) verificaram microvilosidades neste mesmo epitélio. Na mucosa, as fibras musculares lisas penetram nas vilosidades dos intestinos anterior e médio, fato não foi relatado por nenhum dos autores pesquisados. Chatchavalvanich et al. (2006), na espécie Himantura signifer, não observaram presença de músculo na mucosa na porção posterior do intestino. $O$ mesmo padrão e orientação dos músculos da camada muscular foi feito por Morrison (2007); Maciel et al., (2012).

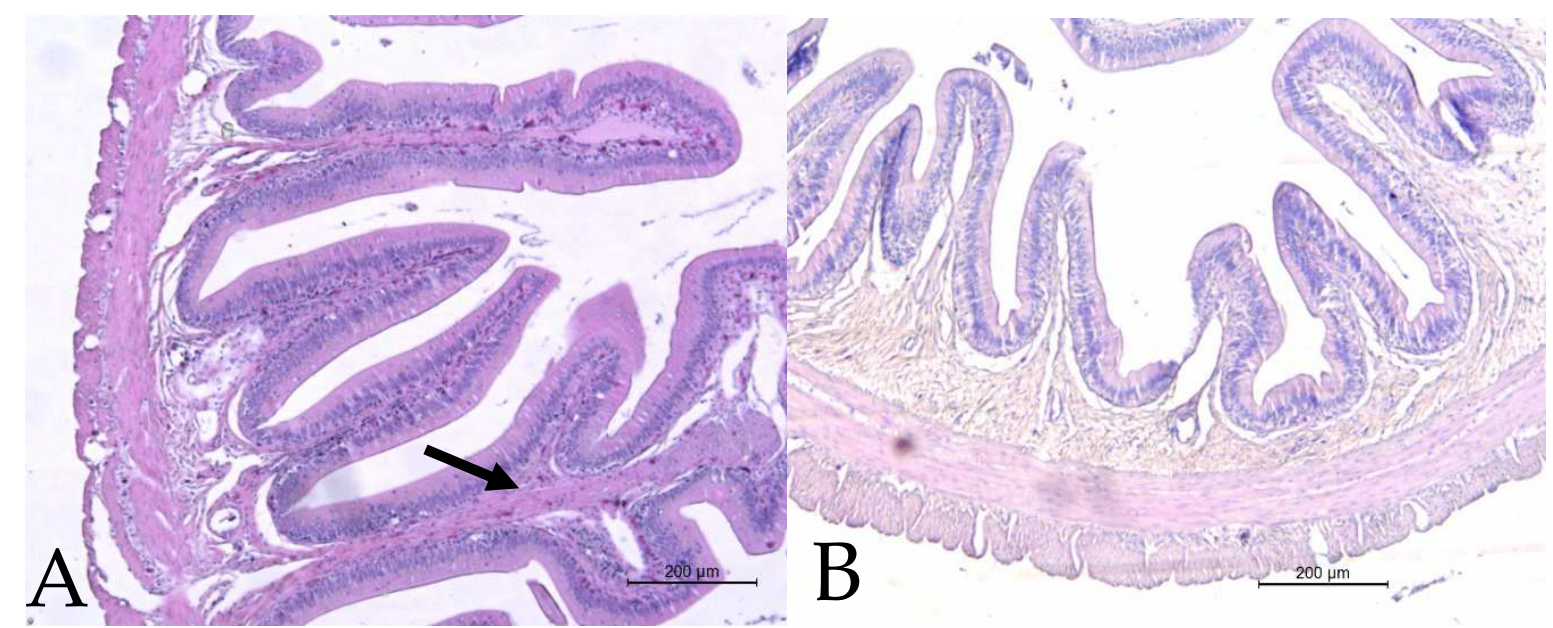

FIGURA 9: Fotomicroscopia de intestino médio (A) e posterior (B) de Pirapitinga, ambos apresentam vilosidades mais curtas que as da porção anterior do intestino. Invasão de fibras musculares no interior das vilosidades (seta) do intestino médio e sua ausência no intestino posterior é o principal diferencial entre as duas porções. HE. $50 \mathrm{x}$.

Devido às escassas informações, na literatura pesquisada, sobre pirapitingas a discussão foi embasada em outras espécies de peixes redondos com aspectos similares aos da espécie Piaractus brachypomus.

\section{CONCLUSÕES}

A organização histológica dos órgãos estudados neste experimento mostrou-se bastante semelhante à de outros peixes, no entanto, algumas particularidades da espécie foram observadas, fato que facilitará futuros estudos relacionados aos diferentes processos patológicos ainda presentes na piscicultura nacional. Maior informação sobre a espécie também auxiliará no aprimoramento do manejo do pirapitinga no Estado de Goiás.

\section{REFERÊNCIA}

ALMEIDA, S.S.N., COSTA, G.C.; PAULA, F.G. ${ }^{2}$, PORTO, R.N.G.; SANTIN, A.P.I. Descrição histológica de órgãos viscerais de tilápia (Oreochromis niloticus). Enciclopédia biosfera, v.11 n.22; p. 3582-91, 2015. Doi: http://dx.doi.org/10.18677/Enciclopedia_Biosfera_2015_247.

CAVICHIOLO, F. Histologia: ferramenta relevante para estudos em peixes cultivados. In.: OLIVEIRA, A. T.; MARIA, A. N.; GOMES, A. L. et al. Manejo e sanidade de peixes em cultivo. Macapá: EMBRAPA, 2009. Cap 23, p. 602-624. 
Disponível em: http://projetopacu.com.br/public/paginas/203-livro-manejo-esanidade-de-peixes-em-cultivo.pdf. Acesso em: 10 de agosto de 2017.

CHATCHAVALVANICH, K.; MARCOS, R.; POONPIROM, J.; THONGPAN, A.; ROCHA, E. Histology of the digestive tract of the freshwater stingray Himantura signifer Compagno and Roberts, 1982 (Elasmobranchii, Dasyatidae). Anatomy and Embryology, v.211, n.5, p.507-18, 2006.

COSTA, G. M.; ORTIS, R. C.; LIMA, M. G. L.; CASALS, J. B.; LIMA, A. R.; JR, J. R. K. Estrutura morfológica do fígado de tambaqui Colossoma macropomum (Cuvier, 1818). Pesquisa Veterinária Brasileira, v. 32, n. 11, p. 1116-1120, 2012. DOI: http://dx.doi.org/10.1590/S0100-736X2012000900022.

GENTEN, F.; TERWINGHE, E.; DANGUY, A. Atlas Of Fish Histology. Science Publishers, 2009. p. 47-57, 75-110.

LEDIC-NETO, J.; DOTTA, G.; GARCIA, P.; BRUM, A.; GONÇALVES, E. L. T.; MARTINS, M. L. Haematology and melanomacrophage centers of Nile tilapia fed supplemented diet with própolis. Acta Scientiarum. Biological Sciences, Maringá, v.36, n.3, p.263-269, 2014. DOI: http://dx.doi.org/10.4025/actascibiolsci.v36i3.22024

MACIEL, P. O.; RODRIGUES, A. P. O.; KIRSCHNIK, L. N. G.; MORON, S. E. Anatomia e histologia funcional do rim e baço de alevinos de pirarucu (Arapaima gigas). In: Congresso da Sociedade Brasileira de Aquicultura e Biologia Aquática, 5., 2012, Palmas. Unir, consolidar e avançar. Anais. Palmas: AQUABIO, 2012.

Disponível

em:

http://ainfo.cnptia.embrapa.br/digital/bitstream/item/64555/1/R0375-2.pdf.

MORRISON, J. Normal Histology. In.: MUMFORD, S.; HEIDEL, J.; SMITH, C.; et al. Fish histology and histopathology. USFWS-NCTC, 2007. Cap. 2, p. 12-42. Disponível em: http://nctc.fws.gov/resources/course-resources/fishhistology/Fish_Histology_Manual_v4.pdf. Acesso em 10 ago. 2014.

OLIVEIRA, D.M.F., SOARES, P.R.L., ANDRADE, A.L.C., CUNHA, F.M., CADENA, P.G. Caracterização morfológica do fígado de oscar (Astronotus ocellatus). In: XIII Jornada de Ensino, Pesquisa e Extensão, 2013, Pernanbuco. UFRPE. Recife. Disponível em: http://www.eventosufrpe.com.br2013/cd/resumos

/R1170-1.pdf. Acesso em: 20 ago. 2017

PAULO, D. V.; FONTES, F. M.; FLORES-LOPES, F. Histopathological alterations observed in the liver of Poecilia vivipara (Cyprinodontiformes: Poeciliidae) as a tool for the environmental quality assessment of the Cachoeira River, BA. Brazilizan Journal of Biology, v. 72, n. 1, p. 131-140, 2012. DOI: http://dx.doi.org/10.1590/S1519-69842012000100015

PEREIRA, S.; PINTO, A. L.; CORTES, R.; FONTAÍNHAS-FERNANDES, A.; COIMBRA, A. M.; MONTEIRO, S. M. Gill histopathological and oxidative stress evaluation in native fish captured in Portuguese northwestern rivers. Ecotoxicology and Environmental Safety, Amsterdam, v. 90, p. 157-166, 2013. DOl: 10.1016/j.ecoenv.2012.12.023. Epub 2013 Jan 23. 
PEREIRA, D.P.; SANTOS, D.M.S.; CARVALHO NETA, A.V.; CRUZ, C.F.; CARVALHO NETA, R.N.F. Alterações morfológicas em brânquias de Oreochromis nilaticus (Pisces, Cichlidae) como biomarcadores de poluição aquática na laguna da Jansen, São Luís, MA (Brasil), Bioscience Journal, Uberlândia, v.30, n.4, p.121321, 2014.

RIBEIRO, F.M; FREITAS, P.V.D.X.; SANTOS, E.O.; SOUSA, R.M.; CARVALHO, T.A.; ALMEIDA, E.M.; SANTOS, T.O.; COSTA, A.C. Alimentação e nutrição de pirapitinga (Piaractus brachypomums) e tambaqui (Colossoma macropomum): revisão, PUBVET, v.10, n.12, p.873-882, 2016a. DOI: htttp://doi.ofg/10.22256/pubvet.v10n12.873-882.

RIBEIRO, L.S.; ALMEIDA, S.S.N.; PAULA, F.G.; PORTO, R.N.G.; SANTIN, A.P.I. descrição histológica de órgãos viscerais de tambacu (Piaractus mesopotamicus $x$ Colossoma macropomum). Enciclopédia Biosfera, Centro Científico Conhecer Goiânia, v.13 n.23; $2016 \mathrm{~b}$. DOI:10.18677/Enciclopedia_Biosfera_2016_036.

SANTOS, E.F.; TAVARES-DIAS, M.; PINHEIRO, D.A.; NEVES, L.R.; MARINHO, R.G.B.; DIAS, M.K.R. Fauna parasitária de tambaqui Colossoma macropomum (Characidae) cultivado em tanque-rede no estado do Amapá, Amazônia oriental. Acta Amazônica, v.43, n.1, p.105-12, 2013. DOI: http://dx.doi.org/10.1590/S004459672013000100013

2016. SIDONIO, L.; CAVALCANTI, I.; CAPANEMA, L.; MORCH, R.; AGALHAES, G.; LIMA, J.; BRUNS, V.; JUNIOR, A. J. A.; MUNGIOLI, R. Panorama da aquicultura no Brasil: desafios e oportunidades - BNDES Setorial. 2012. Disponível em <http://www.bndespar.gov.br/SiteBNDES/export/sites/default/bndes_pt/Galerias/Arq uivos/conhecimento/bnset/set3512.pdf>. Acesso em: 02 fevereiro

SILVA, G.H. Ecoeconomia e pesca esportiva: o meio ambiente como oportunidade sustentável de negócios, Santos-Brasil. 2017, 131f. Dissertação (Mestrado em Direito Ambiental) - Universidade Católica de Santos, Santos, 2017. Disponível em

http://biblioteca.unisantos.br:8181/bitstream/tede/3681/2/Gustavo\%20Henrique\%20 da\%20SIlva.pdf 